\title{
An Introduction to the International Chapters
}

\author{
Joan Marston
}

"There can be no keener revelation of a society's soul than the way in which it treats its' children"

Nelson Mandela

While there are differences across countries in terms of development, access to resources and even the major conditions needing neonatal palliative care, the goals and approaches are the same.

All aim at improving the quality of life of babies and their families. Differences are seen when there is marked health inequality, high levels of poverty, lack of health resources in general, high incidence of infectious conditions and lack of or poor government commitment. Different cultural beliefs and practices can also be seen to influence the need for neonatal palliative care. Neonatal services have too often been the responsibility of non-profit organisations, so it has been encouraging to read of national policies even in developing countries. However, even when policies exist, they are not always funded and implemented.

The strong link between the development of children's palliative care in a country and neonatal services is apparent, and it is pleasing to see neonatal palliative care being integrated into chil-

\footnotetext{
J. Marston $(\triangle)$

International Children's Palliative Care Network (ICPCN), Global Ambassador, Assagay, South Africa e-mail: joanmarymarston@gmail.com
}

dren's palliative care education along with a commitment to research.

International leadership by UNICEF on maternal and child health issues provides promising support, and strengthening of this global support could have very meaningful impact on development. Neonatal palliative care should be considered an essential element of Universal Health Coverage which every country has committed to implement.

From the countries highlighted in the subsequent chapters, we note some very promising developments. However, access to neonatal palliative care remains abysmally poor across some countries and indeed across the world. Yet we have available all that is needed to roll this out to every country and region-education, research, skilled professionals and knowledge, for example government commitment and effective models even in low-resourced countries. Our challenge is to bring all these together and develop powerful advocacy for these most vulnerable babies and families.

My wish is that this excellent textbook will be used across the world to support education and development and that all countries may be challenged to make neonatal palliative care an essential service within their healthcare systems. 